\title{
The risk of cancer in primary care patients with hypercalcaemia: a cohort study using electronic records
}

\author{
F Hamilton ${ }^{\star, 1}$, R Carroll ${ }^{1}$, W Hamilton ${ }^{2}$ and C Salisbury ${ }^{1}$ \\ ${ }^{1}$ University of Bristol, Centre for Academic Primary Care, School of Social and Community Medicine, Canyngne Hall, Bristol BS8 2PS, \\ UK and ${ }^{2}$ University of Exeter, St Luke's Campus, Exeter EX1 2LU, UK
}

Background: The risk of cancer with hypercalcaemia in primary care is unknown.

Methods: This was a cohort study using calcium results in patients aged $\geqslant 40$ years in a primary care electronic data set. Diagnoses of cancer in the following year were identified.

Results: Participants (54267) had calcium results: 1674 (3\%) were $\geqslant 2.6 \mathrm{mmoll}^{-1}$. Hypercalcaemia was strongly associated with cancer, especially in males: OR 2.92,95\% Cl 2.17-3.93, $\mathrm{P}=<0.001$; positive predictive value (PPV) $11.5 \%$; females: OR 1.86, 95\% Cl 1.39-2.50, P<0.001: PPV 4.1\%.

Conclusions: Hypercalcaemia is strongly associated with cancer in primary care, with men at most risk, despite hypercalcaemia being more common in women.

Hypercalcaemia has many causes, the most common being primary hyperparathyroidism and cancer, although nearly all studies originate from secondary care (Fisken et al, 1980; Greaves et al, 1992). In one such secondary care study, 100 out of 145 Japanese patients with corrected calcium $>2.7 \mathrm{mmoll}^{-1}$ had a malignant cause identified (Tokuda et al, 2007). In an earlier UK study at a tertiary centre, 219 of 496 patients with hypercalcaemia had cancer: however, all but four had already been diagnosed with cancer (Fisken et al, 1980). Other UK secondary care studies report cancer in 29-44\% (Harrop et al, 1982; Rajathurai and Cove-Smith, 1984). In contrast, a small Swedish primary care study, using a $2.55 \mathrm{mmoll}^{-1}$ threshold, found only 4 out of 142 patients to have cancer, and 99 patients did not receive a diagnosis (Dalemo et al, 2006). To our knowledge, there have been no UK primary care studies, so we aimed to calculate the prospective risk of cancer in hypercalcaemic patients without a prior diagnosis of malignancy.

\section{MATERIALS AND METHODS}

This was a retrospective cohort study of UK primary care patients in the General Practice Research Database (GPRD)-now the
Clinical Practice Research Datalink. These data include all diagnoses and laboratory investigations from primary care.

Participants. Participants in this study were a control group from a previous study (DISCOVERY), and were patients aged $\geqslant 40$ years who were age- and sex-matched controls to case patients with one of 13 common cancers. Controls were excluded if they had the same cancer as their case, but they could have any other cancer. These control patients are described as 'participants' henceforth. We studied all participants with a calcium result between January 2000 and June 2009, defining those $>2.6 \mathrm{mmoll}^{-1}$ on any occasion as hypercalcaemic, with their first elevated calcium level as the index date. In normocalcaemic participants, the date of their first calcium test was assigned as their index date. The sole exclusion criterion for all participants was a past or current diagnosis of non-skin cancer. Non-skin cancers were identified in the year after the index date and categorised the by cancer site.

Analysis. The main analytical method was logistic regression. Secondary analyses categorised hypercalcaemia into: 2.6-2.79, $2.8-2.99$, and $\geqslant 3 \mathrm{mmoll}^{-1}$, and estimated positive predictive values (PPVs) for cancer in the next year directly. Stata 12 (Statacorp,

*Correspondence: Dr F Hamilton; E-mail gushamilton@gmail.com

Received 24 March 2014; revised 7 July 2014; accepted 10 July 2014; published online 5 August 2014

(C) 2014 Cancer Research UK. All rights reserved 0007 - 0920/14 
College Station, TX, USA) was used for all analyses. A power calculation, using a $4 \%$ difference in cancer outcomes between hypercalcaemic and normocalcaemic participants ( $80 \%$ power, $5 \%$ alpha) suggested a sample size of 5085 would be required, although many more were available.

\section{RESULTS}

Participants (54267) had a calcium value during the study. Their demographics, summary calcium values and cancer outcomes are shown in Table 1 . Table 2 shows the multivariable analysis separated by the genders, as the associations between hypercalcaemia and cancer were strikingly different. The PPVs (95\% binomial confidence intervals) for cancer in men were $11.5 \%(11.1-11.9)$ for calciums between $2.60-2.79 \mathrm{mmoll}^{-1}, 27.9 \%(27.3-28.4)$ for 2.8-2.99 $\mathrm{mmoll}^{-1}$ and 50.0\% (49.4-50.6) for $>3.0 \mathrm{mmoll}^{-1}$. In women, the corresponding PPVs were $4.1 \%$ (3.9-4.4), $8.7 \%$ (8.3-9.0) and $16.7 \%(16.2-17.1)$. In men, the most prevalent cancers were lung (18 cases, $34 \%$ of total), prostate $(11,21 \%)$, myeloma, colorectal, and other haematological cancers (4 each, $8 \%$ ). Twelve other cancers were identified (19\%). In women, the most prevalent were myeloma $(12,24 \%)$, breast $(9,18 \%)$, other haematological cancers $(5,10 \%)$, lung $(4,8 \%)$, and metastatic cancer with unknown primary $(4,8 \%)$. There were 16 other cancers $(32 \%)$. There was no difference between the calcium levels in the different cancers (Kruskal-Wallis test: $P=0.38$ for men, 0.52 for women).

\section{DISCUSSION}

This paper appears to be the first large primary care study to quantify the risk of cancer in patients with hypercalcaemia.

Table 1. Demographic and clinical details of participants
\begin{tabular}{|l|c|c|}
\hline & $\begin{array}{c}\text { Hypercalcaemic } \\
\text { participants }\end{array}$ & $\begin{array}{c}\text { Normocalcaemic } \\
\text { participants }\end{array}$ \\
\hline Number of patients & 1674 & 52593 \\
\hline Age, years (median, IQR) & $74.6(68-82)$ & $71.3(63-80)$ \\
\hline Male (\%) & $27.5 \%(460)$ & $46.3 \%(24362)$ \\
\hline Calcium (median, IQR) & $2.70(2.63-2.72)$ & $2.32(2.25-2.39)$ \\
\hline $\begin{array}{l}\text { Calcium if cancer } \\
\text { diagnosed (median, IQR) }\end{array}$ & $2.80(2.64-2.83)$ & $2.33(2.26-2.41)$ \\
\hline Cancer within 1 year $(n, \%)$ & $103(6.2 \%)$ & $1571(3.0 \%)$ \\
\hline
\end{tabular}

Table 2. Multivariable analysis of putative explanatory variables for cancer in both genders

\begin{tabular}{|c|c|c|}
\hline Variable & $\begin{array}{l}\text { Males }(n=24822) \\
\text { Odds ratio }(95 \% \mathrm{Cl})\end{array}$ & $\begin{array}{l}\text { Females }(n=29445) \\
\text { Odds ratio }(95 \% \mathrm{Cl})\end{array}$ \\
\hline Age (per year) & $1.04(1.04-1.05)$ & $1.02(1.02-1.03)$ \\
\hline Hypercalcaemia & $2.92(2.17-3.93)$ & $1.86(1.39-2.50)$ \\
\hline \multicolumn{3}{|c|}{ Cancer associations by calcium range } \\
\hline $\begin{array}{l}\text { Calcium } \\
2.6-2.79 \mathrm{mmoll}^{-1}\end{array}$ & $2.18(1.54-3.10)$ & $1.61(1.15-2.24)$ \\
\hline $\begin{array}{l}\text { Calcium } \\
2.8 \text { up to } 3.0 \mathrm{mmoll}^{-1}\end{array}$ & $6.18(2.93-13.0)$ & $2.60(1.05-6.44)$ \\
\hline Calcium $>3.0 \mathrm{mmoll}^{-1}$ & $27.7(10.12-75.7)$ & $8.67(3.58-21.0)$ \\
\hline
\end{tabular}

Previous associations with malignancy were confirmed with a striking difference in the risk of cancer between the genders, and a strong relationship between calcium levels and risk. The fact that our study was based on data from a primary care setting is important, as our results can guide primary care practitioners in investigation of hypercalcaemia; secondary care studies-with their much higher prevalence of cancer-cannot do so.

Strengths and weaknesses of the study. This study was large, giving ample power for the primary outcome. However, the data set does not exactly represent a standard primary care population, being derived from a population matched by age and sex to a cancer population. The incidence of cancer in this study is likely to be higher than in an all-age general population, but equally so for hypercalcaemic and normocalcaemic participants. Hence, the odds ratios in the multivariable analyses should be correct, but the PPVs may be slight overestimates. The study relied on accurate recording of cancer outcomes by GPs, but studies confirm that coding in the GPRD is generally accurate, especially in cancer (Khan et al, 2010; Dregan et al, 2012). However, it is likely some cancers were omitted, for example, a patient dying in hospital from cancer, but the cancer never being added to the primary care records. Assuming this sequence of events is more common in hypercalcaemic patients, this bias will have slightly reduced the PPVs.

We chose a single threshold of $2.6 \mathrm{mmoll}^{-1}$ to define hypercalcaemia. Although this simplified the study, it did not accommodate variation in local laboratory assay methods and normal ranges. Furthermore, we used corrected calcium, adjusted for albumin. This was deliberate as it is the figure most commonly used by GPs. Use of the first raised calcium value ignored any repeat measurements, the results of which could illuminate the clinical situation. Again, this was deliberate.

The alternative of using the highest value would have been of less clinical utility-as the clinician is never in the position of knowing that the result they have actually is the highest value. The final limitation is that we do not know why the GP performed a calcium analysis. As there are multiple reasons for GPs to perform tests, one of which is to look for cancer, the results cannot be extrapolated to the asymptomatic population. It is likely that our participants were more likely to have cancer than the general population, although our comparison group also had calcium testing.

It would have been useful to include other causes for hypercalcaemia, such as endocrine disease, in this analysis, but unfortunately our analysis indicated poor GPRD coding for noncancer diagnoses, as these were often made in secondary care.

Comparison with previous literature. No primary care studies on hypercalcaemia have focussed specifically on cancer, but some have examined hypercalcaemia in the community. In a Swedish community study of hypercalcaemia, 6 out of 127 (5\%) patients had an early diagnosis of cancer (Dalemo et al, 2006). However, it was not reported whether or not the blood test preceded the cancer diagnosis or what the exact follow-up for each patient was, so it is impossible to estimate an annual incidence. By 10 years of followup, 15 (12\%) hypercalcaemic patients had developed cancer. These figures are hard to compare with ours as our follow-up was shorter (to try and avoid unrelated cancers being identified), although are broadly in agreement. As in our study, three-quarters of hypercalcaemic patients were female, but the risk of cancer with hypercalcaemia was higher in males.

Implications for clinical practice. This study should help GPs investigate hypercalcaemia appropriately. Although there have been many reports on the causes and prognosis of hypercalcaemia in secondary care, there is little evidence from primary care. 
The risk of malignancy correlated with the degree of hypercalcaemia, with significant differences between men and women (OR 2.14, $P<0.001$ ). In men, even mild hypercalcaemia $\left(2.6-2.8 \mathrm{mmoll}^{-1}\right)$ conferred a risk of cancer in 1 year of $11.5 \%$. If the calcium was above $2.8 \mathrm{mmoll}^{-1}$, the risk increased to $28 \%$. In women, the risks were much less, with the corresponding figures being $4.1 \%$ and $8.7 \%$. This disparity in risk has not previously been documented in hypercalcaemia, although men in the United Kingdom have a greater risk of cancer in general (NCIN, 2009). It is important to note that malignancy was still uncommon, as most cases of hypercalcaemia in this study were mild.

In men, $81 \%$ of the cancer associated with hypercalcaemia was caused by lung, prostate, myeloma, colorectal and other haematological cancers. In hypercalcaemic men, clinicians should consider the above malignancies, and investigate appropriately. We did not study symptom reporting in our hypercalcaemic participants, although it is likely that many of the patients harbouring malignancy would have had additional diagnostic pointers towards their diagnosis. In primary care, simple investigations for all of these cancers (except for colorectal cancer) are available, so initial cancer investigation may not require specialist referral.

In women, cancer was much less common. This may reflect the lower cancer incidence in general $(2.4 \%$ vs $4.6 \%$, in all participants in this study); alternatively, primary hyperparathyroidism is much more common in women, and is therefore likely to account for some of the benign hypercalcaemia in this study (Mazeh et al, 2012).

\section{CONCLUSIONS}

Hypercalcaemia is known to be associated with cancer, but this study shows that often it can predate the diagnosis of cancer in primary care. It significantly increases the risk of cancer, especially in men, and this effect is related to the degree of hypercalcaemia. However, the overall risk of cancer is still small, especially with minor elevations of calcium levels. Investigation strategies can be designed to use these results, both at an individual level and in developing guidelines for primary care in general.

\section{REFERENCES}

Dalemo S, Hjerpe P, Bostrom Bengtsson K, Boström Bengtsson K (2006) Diagnosis of patients with raised serum calcium level in primary care, Sweden. Scand J Prim Health Care 24: 160-165.

Dregan A, Moller H, Murray-Thomas T, Gulliford MC (2012) Validity of cancer diagnosis in a primary care database compared with linked cancer registrations in England. Population-based cohort study. Cancer Epidemiol 36: $425-429$.

Fisken RA, Heath DA, Bold AM (1980) Hypercalcaemia-a hospital survey. Q J Med 49: 405-418.

Greaves I, Grant AJ, Heath DA, Michael J, Adu D (1992) Hypercalcaemia: changing causes over the past 10 years. BMJ 304: 1284.

Hamilton W, Richard N, Rose P, Walter F. Discovery Programme < http:// www.discovery-programme.org > last accessed 10 September (2013).

Harrop JS, Bailey JE, Woodhead JS (1982) Incidence of hypercalcaemia and primary hyperparathyroidism in relation to the biochemical profile. J Clin Pathol 35: 395-400.

Khan NF, Harrison SE, Rose PW (2010) Validity of diagnostic coding within the General Practice Research Database: a systematic review. Br J Gen Pract 60: e128-e136.

Mazeh H, Sippel RS, Chen H (2012) The role of gender in primary hyperparathyroidism: same disease, different presentation. Ann Surg Oncol 19: 2958-2962.

NCIN (2009) The Excess Burden of Cancer in Men in the UK http:// www.ncin.org.uk/view?rid=74 last accessed 13 September 2013.

Rajathurai A, Cove-Smith R (1984) Hypercalcaemia in Cleveland: a hospitalbased survey. $J$ R Soc Med 77: 742-746.

Tokuda Y, Maezato K, Stein GH (2007) The causes of hypercalcemia in Okinawan patients: an international comparison. Intern Med 46: 23-28.

This work is published under the standard license to publish agreement. After 12 months the work will become freely available and the license terms will switch to a Creative Commons AttributionNonCommercial-Share Alike 3.0 Unported License. 